\title{
Distribuição de Weibull como Modelo de Sobrevivência de Iphiseiodes zuluagai Denmark \& Muma (Acari: Phytoseiidae)
}

\author{
Paulo R. Reis ${ }^{1}$ e Marinéia L. Haddad ${ }^{2}$ \\ ${ }^{1}$ EPAMIG /CRSM, Caixa postal 176, 37200-000, Lavras, MG. \\ ${ }^{2}$ ESALQ /USP, Departamento de Entomologia, Caixa postal 9, \\ 13418-900, Piracicaba, SP.
}

An. Soc. Entomol. Brasil 26(3): 441-444 (1997)
Weibull Distribution as Survival Model of Iphiseiodes zuluagai Denmark \& Muma (Acari: Phytoseiidae)

\begin{abstract}
A study of survival of Iphiseiodes zuluagai Denmark \& Muma based on Weibull's distribution showed that females longevity was greater than that of males; unmated females and males also had a longer longevity than mated ones. Mean longevity for virgin females was 27 days and of mated ones 23 days; for males these data were 14 and 8 days, respectively. Mortality rate increased with time for males and females. However, shape parameter values were near 1 suggesting a constant mortality rate.
\end{abstract}

KEY WORDS: Acari, predaceous mite, longevity, citrus.

RESUMO - Utilizando-se a distribuição de Weibull como modelo de sobrevivência do ácaro predador Iphiseiodes zuluagai Denmark \& Muma (Acari: Phytoseiidae), constatou-se que as fêmeas apresentaram maior longevidade do que os machos, e que tanto fêmeas quanto machos não acasalados apresentaram maior longevidade do que quando acasalados. A longevidade média de fêmeas não acasaladas foi de 27 dias e de acasaladas 23 dias. A longevidade dos machos não acasalados foi de 14 dias e dos acasalados 8 dias. Observou-se que, tanto para fêmeas como para machos, a taxa de mortalidade aumentou com o tempo. Entretanto, as estimativas dos parâmetros de forma foram muito próximos de 1, o que sugere que a taxa de mortalidade foi constante.

PALAVRAS-CHAVE: Acari, ácaro predador, longevidade, citros.

A distribuição de Weibull como modelo de sobrevivência de insetos foi considerada válida por Sgrillo (1982), embora tenha sido, anteriormente, utilizada para estimar a sobrevivência humana e de outros mamíferos, pássaros e rotíferos. As principais vantagens da utilização da distribuição de Weibull para análise da sobrevivência é que através da estimativa de apenas dois parâmetros (â e b) são obtidas informações tanto de longevidade média quanto do tipo de curva de sobrevivência. Outra vantagem é que as observações não necessitam ser realizadas a intervalos constantes, como por exemplo com as tabelas de esperança de vida. O mesmo autor utilizou essa distribuição como modelo de sobrevivência de adultos da broca da canade-açúcar, Diatraea saccharalis (Fabr.) (Lepi- 
doptera: Pyralidae).

A obediência ao modelo de sobrevivência é importante, pois se a longevidade obedece ao modelo, é possível estimar a sobrevivência, e este modelo indica se artrópodes criados em laboratório são comparáveis aos selvagens. $\mathrm{Na}$ produção massal de laboratório (de pragas ou de inimigos naturais) é possível se fazer uma previsão de produção, baseando-se no modelo de sobrevivência, tomando-se por base, por exemplo, a capacidade de postura ou de parasitismo.

Como não foi encontrado relato do uso desse modelo para ácaros, elaborou-se o trabalho com a espécie predadora Iphiseiodes zuluagai Denmark \& Muma (Acari: Phytoseiidae), comumente encontrada em citros (Citrus spp.), com o objetivo de estimar a longevidade média e a variação da taxa de mortalidade do ácaro no tempo.

\section{Material e Métodos}

Foi estimada a sobrevivência de fêmeas e machos de I. zuluagai, acasalados e não, tendo como alimento pólen de mamoneira (Ricinus communis), no Laboratório de Acarologia do Centro Regional de Pesquisa do Sul de Minas/EPAMIG, a $25 \pm 2{ }^{\circ} \mathrm{C}, 70 \pm 10 \%$ de UR e $14 \mathrm{~h}$ de fotofase.

Os ácaros foram criados individualizados, ou formando casais, em arenas de $3 \mathrm{~cm}$ de diâmetro confeccionadas com lâmina plástica flexível, de cor preta, flutuando em água numa placa de Petri de $15 \mathrm{~cm}$ de diâmetro por $2 \mathrm{~cm}$ de profundidade, sem tampa. Em cada placa foram colocadas oito arenas (Reis 1996). A cada 24 horas, sob microscópio estereoscópico, foram retirados os ovos das arenas que continham os casais e observada a mortalidade dos ácaros.

As estimativas dos parâmetros de forma (â) e de escala (b) foram obtidas através do método dos quadrados mínimos, após a linearização do modelo de Weibull, como a seguir: $\ln [-\ln (\mathrm{Px})]=-\mathrm{a} \ln \mathrm{b}+\mathrm{a} \ln \mathrm{x} ; \mathrm{Y}=\mathrm{A}+$ $\mathrm{Bx}$, onde $\ln =$ logaritmo neperiano; $(\mathrm{Px})=$ probabilidade de sobrevivência; $\mathrm{x}=$ tempo (dias); $\hat{a}=\mathrm{B}$ e $\mathrm{b}=\mathrm{e}^{-\mathrm{A} / \mathrm{B}}$. A longevidade média $(l m)$ foi estimada através dos parâmetros â e b com a utilização da função gama: $l m=b$ Г $(1+1 / \hat{a})$. Os dados foram analisados através do programa MOBAE (Haddad et al. 1995).

\section{Resultados e Discussão}

O estudo da sobrevivência de I. zuluagai, mostrou maior longevidade das fêmeas em relação aos machos, e que os ácaros não acasalados, tanto as fêmeas como os machos, apresentaram uma sobrevivência maior do que quando acasalados. A redução da longevidade, para machos e fêmeas acasalados, já foi verificada para outras espécies de ácaros, como por exemplo Phytoseiulus macropilis (Banks) (Prasad 1967) e Euseius alatus DeLeon (Reis \& Alves 1997), cujas causas não foram discutidas. A maior longevidade de fêmeas, em relação a machos, deve estar relacionada à maior reserva de energia que possuem, a qual perdem quando acasaladas e produzem ovos, reduzindo assim a longevidade. Machos acasalados também têm a longevidade reduzida por perda de energia. De maneira geral, para Phytoseiidae, Sabelis (1985) relata que fêmeas não acasaladas têm vida mais longa e não produzem ovos, não mencionando as prováveis causas para a maior longevidade.

A longevidade média das fêmeas não acasaladas foi de aproximamente 27 dias (Fig. 1A) e das acasaladas de 23 dias (Fig. 1B). A curva de sobrevivência para ambos os casos foi do tipo I, ou seja, a taxa de mortalidade aumenta com o tempo (â $>1)$.

A longevidade média dos machos não acasalados foi cerca de 14 dias (Fig. 1C) e dos acasalados de 8 dias (Fig. 1D). A curva de sobrevivência para machos não acasalados também foi do tipo I, aumentando a taxa de mortalidade com o tempo (â $>1$ ). Para machos acasalados houve uma dependência de sobrevivência do tipo III, em que a taxa de mortalidade diminui com o tempo (â $<1)$.

A Tabela 1 contém os resultados das estimativas dos parâmetros de forma (â), de escala (b), longevidade média $(\mathrm{lm}), \chi^{2}$ calculado e graus de liberdade (GL). Para 

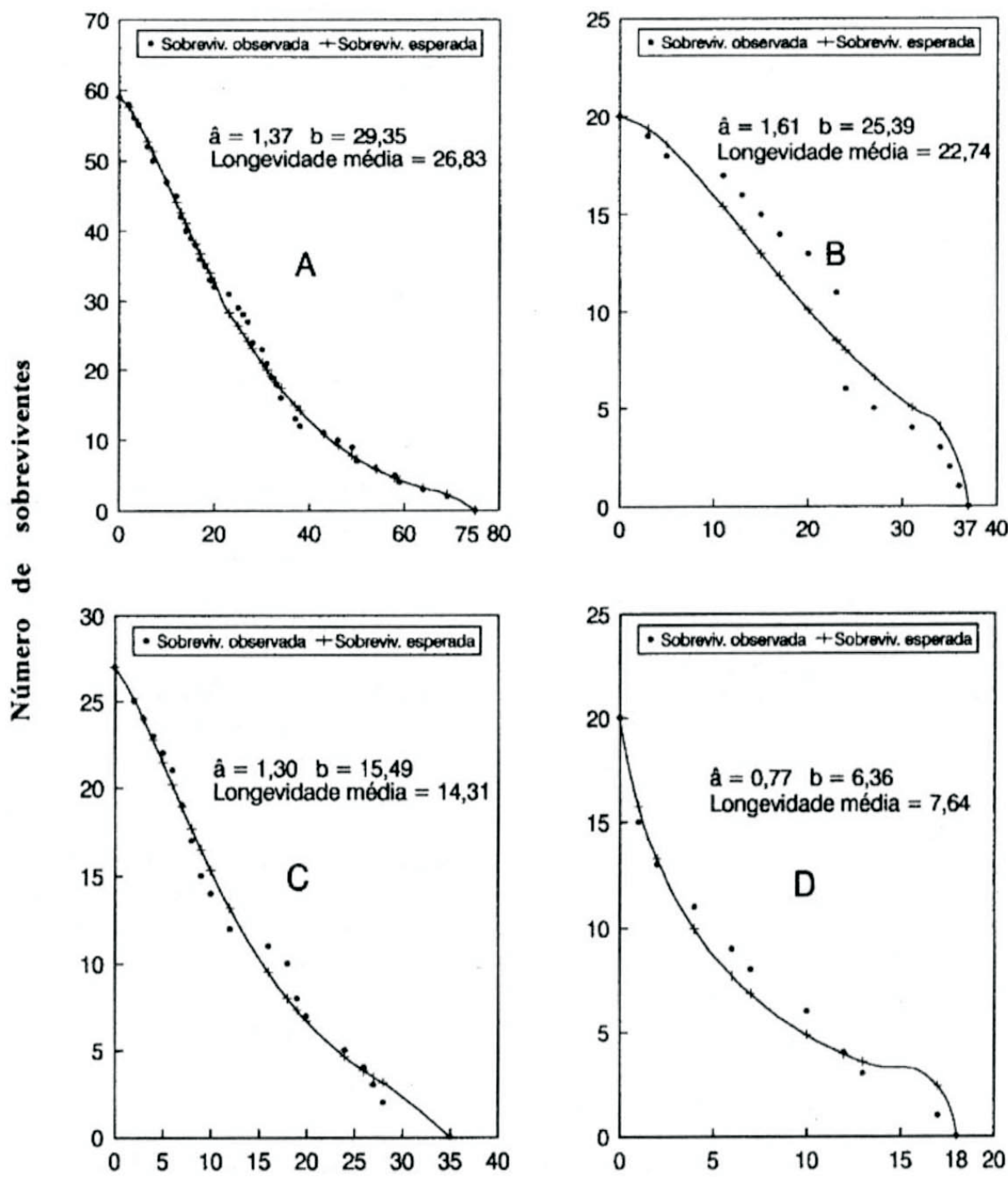

\section{Tempo (dias)}

Figura 1. Sobrevivência e longevidade de Iphiseiodes zuluagai estimadas pelo modelo de Weibull: (A) Fêmeas não acasaladas; (B) Fêmeas acasaladas; (C) Machos não acasalados e (D) Machos acasalados.

todos os casos estudados, o $\chi^{2}$ calculado foi menor que o tabelado, indicando que os dados se ajustam à distribuição de Weibull, ao nível de 5\% de significância. Portanto para o estudo da sobrevivência de I. zuluagai, a distribuição de Weibull se ajustou satisfatoriamente. Observa-se que os valores de â estão muito próximos de 1 , o que sugere que a taxa de 
Tabela 1. Estimativas dos parâmetros de forma (â) e de escala (b) da distribuição de Weibull aplicada à sobrevivência de fêmeas e machos de Iphiseiodes zuluagai, acasalados e não, e respectivas longevidades médias $(\mathrm{lm})$ a $25 \pm 2{ }^{\circ} \mathrm{C}, 70 \pm 10 \%$ de UR e 14 h de fotofase.

\begin{tabular}{lccccccc}
\hline Sexo & Acasalamento & $\mathrm{n}$ & $\hat{\mathrm{a}}$ & $\mathrm{b}$ & $\operatorname{lm}(\operatorname{dias})$ & $\chi^{2}$ & $\mathrm{GL}$ \\
\hline \multirow{2}{*}{ Fêmea } & Não & 59 & 1,37 & 29,35 & 26,84 & 2,54 & 34 \\
& Sim & 20 & 1,61 & 25,39 & 22,74 & 6,63 & 12 \\
\multirow{2}{*}{ Macho } & Não & 27 & 1,30 & 15,49 & 14,31 & 1,73 & 16 \\
& Sim & 20 & 0,77 & 6,38 & 7,64 & 1,72 & 7 \\
\hline
\end{tabular}

mortalidade pode ser considerada constante para todos os casos estudados. Tal observação está de acordo com o formato da curva tipo III de Slobodkin (1962), citado por Southwood (1978), onde a taxa de mortalidade é considerada constante.

Em criações massais de I. zuluagai, para uso em controle biológico, o modelo de sobrevivência testado pode ser de grande valia para previsão de produção e controle de qualidade.

\section{Agradecimentos}

Ao Prof. Dr. José R. P. Parra, Departamento de Entomologia da ESALQ/USP, pelas sugestões e correção do texto original.

\section{Literatura Citada}

Haddad, M.L., R.C.B. Moraes \& J.R.P. Parra. 1995. Modelos bioestatísticos aplicados à entomologia; MOBAE, versão 1.0. Piracicaba, ESALQ/USP, 44 p.

Prasad, V. 1967. Biology of the predatory mite Phytoseiulus macropilis in Hawaii (Acarina: Phytoseiidae). Ann. Entomol. Soc. Am. 60: 905-908.
Reis, P.R. 1996. Aspectos biológicos e seletividade de agroquímicos a Iphiseiodes zuluagai Denmark \& Muma (Acari: Phytoseiidae). Tese de doutorado, ESALQ/USP, Piracicaba, 154p.

Reis, P.R. \& E.B. Alves. 1997. Biologia do ácaro predador Euseius alatus DeLeon (Acari: Phytoseiidae). An. Soc. Entomol. Brasil 26: 143-147.

Sabelis, M.W. 1985. Reproduction. p.73-82. In: W. Helle \& M.W. Sabelis (eds.) Spider mites; their biology, natural enemies and control. Amsterdam, Elsevier, v.1B, 458p.

Sgrillo, R.B. 1982. A distribuição de Weibull como modelo de sobrevivência de insetos. Ecossistema 7: 9-13.

Southwood, T.R.E. 1978. Ecological methods with particular reference to the study of insect populations. 2.ed. London, Chapman and Hall, 524 p.

Recebido em 07/10/96. Aceito em 12/09/97. 